\title{
INTRODUCTION TO SPATIAL ECONOMETRICS
}

James LeSage ve R. Kelley Pace (2009), Chapman and Hall/CRC, 374 sayfa, ISBN: 978-1420064247

Mekânsal ekonometrinin çeşitli alanlarda kullanımı özellikle son yıllarda yoğun bir artış göstermektedir. "Mekân" ya da "konum" kavramının neden modelleme sürecine dahil edilmesi gerektiğini ise Tobler (1970)'in şu ifadesi açıklamaktadır: Buna göre; uzaydaki her şeyin birbirini etkilemekte, ancak bu etki uzaklığa bağlı olarak azalmaktadır. Sosyal bilimler alanında, söz konusu etkilerin varlığı, grup normu, referans ya da rakip grubun etkisi adı altında uzun zamandır tartış1sa da, modelleme sürecini nasıl değiştirdiği Anselin (1988)'in çalışmasına kadar kapsamlı bir biçimde ele alınmamıştır. Anselin (1988) konumun, ekonometrik yöntemlerde siklıkla kullanılan varsayımları nasıl ihlal ettiğini göstermiş ve mekânsal yöntemleri temel olarak ikiye ayırmıştır: Mekânsal otoregresif yöntemler ve mekânsal hata modeli. Bilindiği gibi, bu yöntemlerin tamamında analiz birimleri arasındaki uzaklık bir matris yardımıyla modele dahil edilmektedir. Mekânsal otoregresif modellerde, yalnızca bağımlı değişken bir uzaklık matrisi yardımıyla mekânsal gecikmeli değişken haline getirilmektedir. Böylece komşulardaki bağımlı değişkenin modeldeki bağımlı değişken üzerindeki etkisi incelenebilmektedir. Hata terimleri arasında konumdan kaynaklanan bağımlılığın yok edilmesi için ise geliştirilen model mekânsal hata modelidir.

Mekânsal ekonometri üzerine Anselin (1988)'in çalışmasından bu yana yoğun bir biçimde ilerleme kaydedilse de, özellikle bu alanda çalışmaya başlayanlara rehber niteliğinde bir kitap kolay bulunmamaktadır. LeSage ve Pace (2009)'un Mekânsal Ekonometri'ye Giriş (Introduction to Spatial Econometrics) adlı kitabı ise bu boşluğu doldurması bakımından önemlidir. Ayrıca, kitabın internet sitesinden yazarların modellere ilişkin kendi geliştirdikleri MATLAB kodlarını da indirmek ve kullanmak mümkündür. Böylelikle yazarlar, hem teori hem de ampirik uygulama bakımından araştırmacılara yol göstericilik yapmaktadırlar.

LeSage ve Pace (2009), Anselin (1988) tarafindan ilk olarak ortaya konan mekânsal modelleri baştan incelemekte ve açıklamaktadır. Kitabın ilk bölümlerinde öncelikle mekânsal bağımlılık ve mekânsal heterojenlik kavramları üzerinde durulmakta ve bu etkilerin neden olduğu sorunlardan bahsedilmektedir. Mekânsal veri üretim süreci tartışmasının örneklerle desteklenmesi, LeSage ve Pace (2009)'in kitabını özellikle bu alanda çalışmaya 
yeni başlayanlar için cazip hale getirmektedir. Kitabın en önemli unsurlarından birisini de zaten bu bağımlılık çeşidinin ve olası sorunlarının örneklerle açıklanması oluşturmaktadır. Yine de kitabın bir "giriş" niteliğini taşıması açısından en önemli kısmı, mekânsal ekonometri kullanımını gerektiren durumların ve modellerin yorumlanma biçimlerinin açıklandığı ikinci bölümdür denebilir. Bu bölümde daha önce Anselin (1988) tarafindan yapılan model sınıflandırmasına temelde sadık kalınmaktadır. Yine de, mekânsal otoregresif modeller ve mekânsal hata modelleri dışında, açıklayıcı değişkenler üzerinde de komşuluk ilişkilerinin etkisi olabileceğinin üzerinde durulmaktadır. Bir başka ifadeyle LeSage ve Pace (2009), komşuların açıklayıcı değişkenlerinin de kurulan model üzerinde etkili olduğunun altını çizmektedir. Bu duruma örnek olarak, pozitif ve negatif dışsallıkları vermektedir. Örneğin, komşuların bahçe düzenlemeleri bize ait bir evin fiyatını etkileyebilmektedir (s. 30). Öte yandan, bu bölümde, parametre tahminlerinin yorumlanması üzerinde de durulmaktadır. LeSage ve Pace (2009), bir bölgedeki açıklayıcı değişkenin bölgenin kendi üzerindeki etkisini "doğrudan etki”; diğer bölgeler üzerindeki etkisini ise "dolaylı etki" olarak ayrıştırmakta ve bunların toplamını da "toplam etki" olarak adlandırmaktadır. Mekânsal regresyon modellerinin bu etkileri yansitması da onu klasik regresyon modellerinden ayıran ve katsayıların yorumunu değiştiren önemli bir özelliktir. Bu konu hakkında ayrıntılı bir başka çalışma için LeSage ve Fischer (2008)'e de bakılabilir.

LeSage ve Pace (2009), açıklayıcı değişkenlerin de mekânsal anlamda dikkate alındığı iki ayrı modelden söz etmektedir. Bunlardan ilki komşuluk ilişkilerinin yalnızca açıklayıcı değişkenler üzerindeki etkisini inceleyen mekânsal X modelidir (s. 30). Mekânsal X modelinde, bağımsız değişken veya değişkenlerden biri uzaklık matrisi ile çarpılır; böylelikle yakın ve uzaktaki komşuların etkisi ayrıştırılabilir. Diğer pek çok mekânsal modelin aksine, mekânsal X modeli için ayrı bir tahmin yöntemine gerek yoktur. En küçük kareler yöntemi, parametre tahmini için etkinliğini sürdürecektir. Söz konusu ikinci model ise, açıklayıcı değişkenin yanı sıra, bağımlı değişkenin de bir uzaklık matrisi ile mekânsal gecikmeli hale getirildiği mekânsal Durbin modelidir. Aslında, bu son modelin literatürde telaffuz edilmesi LeSage ve Pace (2009)'in çalışmasından daha önceye Anselin (1988)'e dayanır. Ne var ki Anselin (1988), bu model tipinin üzerinde fazla durmamıştır. LeSage ve Pace (2009) ise, özellikle altıncı bölümde, mekânsal modeller arasında seçim yaparken ilk tercihin mekânsal Durbin modeli olması gerektiğini savunmaktadır. Nitekim Elhorst (2010)'a göre, LeSage ve Pace (2009)'in kitabının en önemli katkılarından birinin de bu son modelin ayrıntılı bir biçimde ele alınması olduğunu vurgulamaktadır.

LeSage ve Pace (2009: 156-157), bağımlı değişkendeki mekânsal bağımlılığın gözden kaçırılmasının modelleme sürecinde önemli sapmalara ve 
katsayıların yanlış yorumlanmasına neden olacağını belirtmektedir. Öte yandan, hata terimleri arasındaki mekânsal bağımlılık ise parametre tahmininde etkinlik kaybı yaratmaktadır. Mekânsal Durbin modeli ise, mekânsal otoregresif ve mekânsal hata modellerinin ikisini de içinde barındırdığından daha doğru bir başlangıç noktası oluşturacaktır. Bu anlamda, Elhorst (2010)'un da belirttiği üzere "genelden özele" giden bir model seçimi izlenmesi önerilmektedir. Daha sonra, parametrelerin sıfirdan farklı olup olmamasına göre mekânsal modeller arasında bir tercih yapılabilir (Elhorst 2010). Mekânsal $\mathrm{X}$ modeli de dahil olmak üzere hiçbir modelin uygun olmadığının tespiti halinde en küçük kareler yöntemi en etkin ve sapmasız tahminleri sağlayacaktır. Kitabın altıncı bölümünde yer alan örnek ve örneğe ait yorum ise model seçimi yapacak olan araştırmacıya özellikle yardımcı olacaktır.

LeSage ve Pace (2009)'in kitabını alandaki diğer kaynaklardan ayıran ve isminde geçen "giriş" niteliğini değiştiren bir başka özelliği de mekânsal modellere Bayesci bir yaklaşım getirmiş olmasıdır. Aslında, mekânsal modellerin tahmininde yoğun olarak maksimum olabilirlik yöntemi kullanılmaktadır ve kitabın üçüncü ve dördüncü bölümlerinde de gerek bu yönteme, gerekse büyük örneklemlerde ortaya çıkan hesaplama güçlüklerine ve çözüm önerilerine değinilmiştir. Kitabın beşinci bölümü ise, literatürde daha önce fazla tartışılmamış bu yaklaşıma ayrılmıştır. LeSage ve Pace (2009), Markov Zinciri Monte Carlo (MZMC) yöntemi yardımıyla karmaşık parametre tahminlerinin daha basit problemlere indirgenebildiğini; böylelikle de mekânsal modeller ve tahminlerde Bayesci yöntemlerin diğer yöntemlere kıyasla daha kolay uygulanabildiğini belirtmektedir. Buna göre, Bayesci MZMC tahminlerinin birkaç temel üstünlüğü bulunmaktadır. İlk olarak MZMC, basit mekânsal otoregresif modeli, heteroskedastisiteyi ve uç değerleri de kapsayacak şekilde genişletmektedir. İkinci olarak, bu yöntem "doğrudan", "dolaylı" ve toplam etkilere ilişkin geçerli tahminler sunmakta, böylelikle açıklayıcı değişkenin bağımlı değişkenler üzerindeki etkisinin yorumlanabilmesine katkıda bulunmaktadır. Son olarak, Bayesci MZMC koşullu olasılık tabanlı bir tahmin gerçekleştirdiğinden özellikle birden fazla mekânsal ağırlık matrisinin söz konusu olduğu modellerde önemli bir hesaplama kolaylığı sağlamaktadır.

Kitabın yedinci bölümü ise, mekân-zaman (spatiotemporal) modellere odaklanmıştır. $\mathrm{Bu}$ modeller, bölgelerin kendi karakteristiklerinin yanı sıra, komşu bölgelerin geçmiş dönemlerdeki karakteristiklerinden de etkilendiğini varsaymaktadır. Buna göre, diğer mekânsal modellerden farklı olarak eş zamanlı değil, mekân ve zaman anlamında gecikmeli bir etki söz konusudur. Yazarlar burada aslında Anselin (1988)'de belirtilen eş zamanlılık varsayımını ortadan kaldırmaktadır. Mekân - zaman modelleri, bu çerçevede gecikmeli bir mekânsal değişkenin yer aldığı dinamik panel veri modelleri olarak ele 
alınabilir. LeSage ve Pace (2009: 189), bu modellerin uzun dönemde eş zamanlı mekânsal ilişkilere neden olduğunu belirtmektedir. Bu bölüm aynı zamanda, mekân - zaman modelleri ile önceki bölümlerde anlatılan mekânsal modeller arasındaki ilişkiyi de açıklamaktadır.

Kitabın sonraki bölümü ise mekânsal etkileşim modelleri ile mekânsal ilişkilerin önemli olduğu modellere ayrılmış̧ır. Mekânsal etkileşim modelleri, temel olarak, yerçekimi modellerindeki (gravity models) gözlemlerin birbirinden bağımsız olma varsayımını kaldırarak başlangıç ve varış noktaları arasındaki bağımlılığı dikkate almaktadır. Kitabın bu bölümü aslında LeSage ve Pace (2008)'in daha önce yayınlanan çalışmalarına dayanmakta ve maksimum olabilirliğin yanı sıra Bayesci MZMC tahmin yöntemlerini de ele almaktadır. Söz konusu yöntemlerin ABD'deki eyaletler arasındaki göç akışı örneği üzerinden açıklaması, araştırmacıya özellikle yön gösterici olmaktadır.

Burada ayrıntıyla sayılan bölümlere ek olarak, kitapta örneğin ikili düzende tanımlanmış bağımlı değişkenleri içeren mekânsal probit ve mekânsal tobit yöntemlerinde de bahsedilmektedir. Özetle LeSage ve Pace (2009), bu kitapta mekânsal ekonometriye yeni başlayanlar için modeller ve onların dayandığı temeller hakkında örneklerle bilgi vermenin de ötesinde şimdiye kadar yaygın bir biçimde ele alınmamış diğer model ve tahmin yöntemlerinden de bahsetmektedir. Aynı anda hem temel hem ileri düzey bir çalışma ortaya koymuşlardır. Bu şekliyle, LeSage ve Pace (2009)'in kitabı mekânsal ekonometri ile ilgilenen herkesin araştırmalarına kaynaklık edebilecek çok değerli bir eser haline gelmiştir.

Dr. Sevgi Eda Tuzcu

Ankara Üniversitesi

Siyasal Bilgiler Fakültesi

\section{Kaynakça}

Anselin, Luc (1988), Spatial Econometrics: Methods and Models (Dordrecht: Kluwer Academic Publishers).

Elhorst, J. Paul (2010), "Applied Spatial Econometrics: Raising the Bar", Spatial Economic Analysis, 5 (1): 9-28.

LeSage, James P. ve Manfred M. Fischer (2008), "Spatial Growth Regressions: Model Specification, Estimation and Interpretation", Spatial Economic Analysis, 3 (3): 275-304.

LeSage, James P. ve R. Kelley Pace (2008), "Spatial Econometric Modeling of Origin-Destination Flows", Journal of Regional Science, 48 (5): 941-967.

LeSage, James P. ve R. Kelley Pace (2009), Introduction to Spatial Econometrics (Florida: Chapman and Hall).

Tobler, Waldo R. (1970), "A Computer Movie Simulating Urban Growth in the Detroit Region" Economic Geography, 46 (Supplement: Proceedings): 234-240. 